\title{
Outcome of post-traumatic unawareness persisting for more than a month
}

\author{
Ivan Dubroja, Štefica Valent, Pavle Miklić, Đurđica Kesak
}

\section{Hospital for}

Rheumatic Diseases and Rehabilitation, Krapinske Toplice, Croatia

I Dubroja

Š Valent

Đ Kesak

Department of Neurosurgery, School of Medicine,

University of Zagreb, Croatia

P Miklić

Correspondence to: Dr I Dubroja.

Received 29 March 1993 and in final revised form 7 November 1994

Accepted 11 November 1994

\begin{abstract}
From 1986 to the end of 1991,19 patients with persisting post-traumatic unawareness were admitted for rehabilitation. Criteria for admission were head trauma, Glasgow coma scale score $\leqslant 8$ points, and at least a one month duration of unawareness.

Out of 19 patients, 12 patients (63\%) regained consciousness, 11 patients $(58 \%)$ within the first year and one patient $(5 \%)$ within the second year. The mean duration of unawareness in the patients who recovered consciousness was 190 (range 62-440) days.

In the recovery group, according to the Glasgow outcome scale, seven out of 12 patients $(58 \%)$ were moderately disabled and five $(42 \%)$ were severely disabled at the moment of discharge from rehabilitation. All the 12 patients who regained consciousness live with their families, and none had to be kept in an institution.

The data confirm that awakening from post-traumatic unawareness is possible after a long period. Therefore, post-traumatic unawareness persisting for more than a month should not be considered an irreversible condition, because an outcome that might be regarded by some as being acceptable is possible even in patients with very severe brain damage.
\end{abstract}

(F Neurol Neurosurg Psychiatry 1995;58:465-466)

Keywords: head trauma; post-traumatic unawareness; Glasgow outcome scale

Some studies report $1 \%$ to $2 \%$ of patients admitted to hospital due to severe head trauma, in whom coma persists for more than a month. ${ }^{4}$

The aim of this study was to assess the extent to which the vegetative state is an irreversible condition and whether it is possible for such patients to achieve a certain quality of life with possible reintegration into the family and society.

\section{Patients and methods}

From 1986 to the end of 1991,19 patients (15 males and four females, mean age 24 years) with fully developed post-traumatic unawareness were admitted after primary neurosurgical care, to the postintensive care unit of the neurological rehabilitation ward of the Hospital for Rheumatic Diseases and Rehabilitation in Krapinske Toplice, Croatia.

Criteria for admission were head trauma, Glasgow coma scale score $\leqslant 8$ points, and duration of post-traumatic unawareness of at least one month. ${ }^{8}$

Trauma was caused by traffic accidents in $16(84 \%)$ patients, by fall in two (11\%), and by a hammer blow in one $(5 \%)$. Spastic tetraparesis was present in 15 patients, spastic tetraplegia in three, and flaccid tetraplegia in one.

The rehabilitation programme was individually designed and adjusted for each patient according to his physical condition and existing complications. Besides the interdisciplinary medical team, the closest family member, usually the mother, was actively included in the rehabilitation process as a "layman therapist", where possible.

During the coma period, all patients The grade of brain damage due to a traumatic event may range from discrete motor or cognitive impairment to coma. If patients do not recover from the mesencephalic syndrome within a few weeks, they may develop prolonged post-traumatic unawareness; the vegetative state: the body cyclically awakens and sleeps, but expresses no behavioural or cerebral metabolic evidence of possessing cognitive function or of being able to respond in a learned manner to external events or stimuli. ${ }^{12}$

Few data are available in the medical literature on patients with traumatic brain injury unaware for periods longer than one month, and especially longer than six months. ${ }^{3-7}$ received continuous peripheral stimulation treatment consisting of visual, auditory, olphactory, kinaesthetic, and thermal stimulation. The patient's capacity to execute simple commands in a learned, repetitive manner was used to differentiate between the unaware and aware patients.

After waking from coma, the patients were transferred to the neurological rehabilitation ward, where classic methods of neurorehabilitation were applied. Towards the end of their stay in hospital and before discharge, recovery was estimated according to the Glasgow outcome scale. $^{9}$ 


\section{Results}

Twelve out of 19 patients (63\%) with posttraumatic unawareness regained consciousness, $11(58 \%)$ within the first and one (5\%) within the second year of the follow up period.

In 12 patients who regained consciousness, the mean duration of unawareness was 190 (range 62-440) days. Eight of them were unaware for more than six months (range 190-440 days). At the end of the follow up period, in the recovery group, according to the Glasgow outcome scale, seven out of 12 patients $(58 \%)$ were moderately disabled and five $(42 \%)$ were severely disabled at the moment of discharge from rehabilitation. All the 12 patients who regained consciousness live with their families, and none had to remain in an institution. The mean duration of unawareness was 239 days for severely disabled patients, and 126 days for moderately disabled patients.

Complete or good recovery from post-traumatic unawareness was not achieved in any of the patients.

During the period of hospital rehabilitation, all 19 patients $(100 \%)$ had urinary and respiratory infections and $12(63 \%)$ were tracheotomised due to insufficient respiration. Post-traumatic seizures occurred in 11 $(58 \%)$, hydrocephalus was found in 11 $(58 \%)$, and chronic subdural haematoma in two patients (11\%).

\section{Discussion}

Stages of remission of the vegetative state are characterised by gradual recovery of higher cortical functions accompanied by subsidence of primitive motor patterns until their complete or partial disappearance. ${ }^{1}$ Whereas complete recovery from the vegetative state is not recorded, a less satisfactory outcome, still allowing community reintegration, may occur.

During rehabilitation in the hospital, 12 out of the 19 patients $(63 \%)$ regained consciousness, and seven out of these $12(58 \%)$ were discharged from the hospital in a state of moderate disability.

In the study of Groswasser and Sazbon,? about $54 \%$ of 134 patients who were in prolonged post-traumatic unawareness persisting for more than one month regained consciousness. The mean time required to regain consciousness was $11 \cdot 3$ (SD $8 \cdot 9$ ) weeks. Our patients were in a coma for much longernamely, $27 \cdot 1$ weeks. It is worth mentioning that one patient in our study regained consciousness after 440 days (62.8 weeks). Higashi et $a l^{3}$ report that only $10 \%$ of patients regained consciousness from coma $30 \%$ of patients included were comatose due to a traumatic brain injury), with a total mortality of $73 \%$. In our study, the mortality was $11 \%$, but attention must be paid to the fact that in their study patients were recruited at a time after injury that is not documented.

Bricolo et al ${ }^{10}$ found that $13 \%$ of patients with post-traumatic unawareness were able to obey commands after the third month, whereas only $1.5 \%$ of the patients began to follow commands after six months.

A study by Levin et al $^{4}$ showed that $52 \%$ of the patients recovered consciousness within the first year of the follow up period, and $58 \%$ improved by the end of the three-year follow up, which is consistent with our data.

Data on the outcome in patients with posttraumatic unawareness persisting for more than one month are rare. The study by Groswasser and Sazbon ${ }^{7}$ describes four patients who recovered consciousness after more than six months, with very poor outcome: none of them could live at home with their families, and they all had to remain in an institution. We had eight patients with post-traumatic unawareness that persisted for more than six months (range six to 15 months). Five of them have recovered to the severe disability stage, and three have recovered to the moderate disability stage. All the patients live at home now.

In the recovery group, a satisfactory outcome (moderate disability) was achieved in a higher percentage of patients than in other studies. ${ }^{47}$ Complete recovery from the vegetative state was not achieved by any patient in our study.

Our data confirm that recovery from the vegetative state is possible after a long period - even after more than six months. Therefore, post-traumatic unawareness persisting for more than a month should not be considered an irreversible condition, and even in patients with very severe brain injury it is possible to achieve an outcome that might be regarded by some as being acceptable.

1 Gerstenbrand F, Saltuari L, Kofler M, Formisano R Clinical evaluation of the severe brain injury. Neurologija 1990;32(suppl 1):71-88.

2 Council on Scientific Affairs and Council on Ethical and Judicial Affairs. Persistent vegetative state and decision to withdraw or withhold life support. $¥ A M A 1990 ; 263$ : 426-30.

3 Higashi K, Katano M, Abiko S, Ihara S, Katayama S, Wakuta Y, Okamura T, Yamashita T. Five-year followup study of patients with persistent vegetative state. f Neurol Neurosurg Psychiatry 1981;44:552-4.

4 Levin HS, Saydjari C, Eisenberg HM, Foulkes M, Marshall LF, Ruff RM, Jane JA, Marmarou A Vegetative state after closed-head injury: a traumatic Vegetative state after closed-head injury: a traum
coma data bank report. Arch Neurol 1991;48:580-5.

5 Grahm TW, Williams FC, Harrington T, Spetzler RF Civilian gunshot wounds to the head: a prospective Civilian gunshot wounds to the head:
study. Neurosurgery 1990;27:696-700.

6 Braakman R, Jennet WB, Minderhound JM. Prognosis of the posttraumatic vegetative state. Acta Neurochir (Wien) 1988;95:49-52

7 Groswasser Z, Sazbon L. Outcome in 134 patients with prolonged posttraumatic unawareness. Part 2: functional outcome of 72 patients recovering consciousness f Neurosurg 1990;72:81-4.

8 Teasdale G, Jennet B. Assessment of coma and impaired consciousness: a practical scale. Lancet 1974;2:81.

9 Jennet B, Bond M. Assessment of outcome after severe brain damage. Lancet 1975;1:480-4.

10 Bricolo A, Turazzi S, Feriotti G. Prolonged posttraumatic unconsciousness. F Neurosurg 1980;52:625-34. 